\title{
Bioquímicos séricos em cordeiros mestiços: influência do estresse calórico
}

Francisco Augusto Ricci Catalano", Ursula Vanessa Polito, Joao Rafael de Conte Carvalho de Alencar, Guilherme Cazerta Lemos, Natália Machado Rahal, Juliana Regina Peiró, Leydson Formiga Feitosa, Manoel Garcia Neto, Max José de Araujo Faria Junior, Luiz Claudio Nogueira Mendes

Universidade Estadual Paulista (UNESP), Araçatuba, SP, Brasil

*Autor correspondente

e-mail: francisco.ricci@grupointegrado.br

\section{Resumo}

Objetivou-se com esse trabalho comparar o perfil bioquímico sérico de cordeiros mestiços antes e depois de um período de estresse calórico. Para tanto, foram avaliados os perfis bioquímicos de 12 cordeiros mestiços, lanados, com três meses, pesando em média $18 \mathrm{~kg}$. Os animais permaneceram confinados em galpão climatizado (UNESP, Araçatuba) com temperaturas médias de $28^{\circ} \mathrm{C}$, por 34 dias. No $35^{\circ}$ dia de experimento amostras de sangue foram coletadas e os animais foram submetidos a um estresse calórico com temperaturas de $37^{\circ} \mathrm{C}$, por um tempo de 4 horas durante quatro dias consecutivos. No $38^{\circ}$ dia de experimento, ao término do estresse calórico, novas amostras de sangue foram coletadas. Os perfis bioquímicos comparados foram glicose, ureia, creatinina, fosfatase alcalina, aspartato aminotransferase, gamaglutamiltransferase, albumina, proteína plasmática total e fibrinogênio. Os resultados foram submetidos à análise de variância com nível de significância $\mathrm{P}<0,05$. As médias dos bioquímicos séricos glicose, creatinina, albumina e fibrinogênio revelaram-se mais elevados no 38ํㅜ dia de experimento, e os demais bioquímicos demonstraram serem superiores no 35을. A análise de variância revelou diferença significativa $(\mathrm{P}<0,05)$ entre as médias dos bioquímicos séricos glicose $\left(68,75\right.$ no $35^{\circ}$ e 73,75 no 38으 dia), gamaglutamiltransferase $\left(44,95\right.$ no $35^{\circ}$ e 28,99 no $38^{\circ}$ dia), albumina $\left(2,84\right.$ no $35^{\circ}$ e 3,43 no $38^{\circ}$ dia) e fibrinogênio $\left(0,1\right.$ no $35^{\circ}$ e 0,2 no $38^{\circ}$ dia) quando comparados os períodos antes e depois do estresse calórico. Por outro lado, não foram encontradas diferenças significativas em ureia (8,3 no $35^{\circ}$ e 8,0 no $38^{\circ}$ dia), creatinina $\left(0,83\right.$ no $35^{\circ}$ e 0 ,86 no $38^{\circ}$ dia), fosfatase alcalina ( 509 no $35^{\circ}$ e 478 no $38^{\circ}$ dia), aspartato aminotransferase ( 96 no 35o e 87,2 no $38^{\circ}$ dia) e proteína plasmática total (5,8 no $35^{\circ}$ e 5,6 no 38ํ dia). Os bioquímicos glicose, fibrinogênio, ureia e aspartato aminotransferase ficaram dentro dos limites de referência, demonstrando que neste modelo experimental estas variáveis não foram influenciadas pela temperatura ambiental do ponto de vista clínico. Os valores da fosfatase alcalina, proteína plasmática total e creatinina apresentaram divergência nos valores 
de referência, não tendo ligação com a temperatura ambiental. Estes resultados podem estar relacionados com a idade dos animais, que apresentam intensa atividade osteoclástica, redução das globulinas séricas e pouca massa muscular respectivamente. 0 gamaglutamiltransferase reduziu significativamente e abaixo dos níveis de referência no 38º dia, contudo não foi encontrado respaldo científico para esta redução. 0 aumento significativo da albumina (acima dos valores de referência) e do fibrinogênio no $38^{\circ}$ dia pode estar relacionado à hemoconcentração consequente à perda evaporativa pulmonar em função do aumento da temperatura ambiental. Conclui-se que para este modelo experimental os bioquímicos avaliados não sofreram influência ao aumento da temperatura ambiental, exceto pela redução do gamaglutamiltransferase e aumento da albumina. 